Article

\title{
On the Modelling and Control of a Laboratory Prototype of a Hydraulic Canal Based on a TITO Fractional-Order Model
}

\author{
Andres San-Millan ${ }^{1}$, Daniel Feliu-Talegón ${ }^{1}$, Vicente Feliu-Batlle ${ }^{2, *}$ (D) and Raul Rivas-Perez ${ }^{3}$ \\ 1 Instituto de Investigaciones Energéticas y Aplicaciones Industriales, University of Castilla-La Mancha, \\ 13071 Ciudad Real, Spain; andres.sanmillan.rodriguez@gmail.com (A.S.-M.); daniel.feliu@uclm.es (D.F.-T.) \\ 2 Escuela Técnica Superior de Ingenieros Industriales, University of Castilla-La Mancha, \\ 13071 Ciudad Real, Spain \\ 3 Department of Automatic control and Computer Science, Havana Technological University, \\ La Habana 19390, Cuba; rivas@automatica.cujae.edu.cu \\ * Correspondence: vicente.feliu@uclm.es; Tel.: +34-926-295-300 (ext. 90380)
}

Received: 30 June 2017; Accepted: 1 August 2017; Published: 3 August 2017

\begin{abstract}
In this paper a two-input, two-output (TITO) fractional order mathematical model of a laboratory prototype of a hydraulic canal is proposed. This canal is made up of two pools that have a strong interaction between them. The inputs of the TITO model are the pump flow and the opening of an intermediate gate, and the two outputs are the water levels in the two pools. Based on the experiments developed in a laboratory prototype the parameters of the mathematical models have been identified. Then, considering the TITO model, a first control loop of the pump is closed to reproduce real-world conditions in which the water level of the first pool is not dependent on the opening of the upstream gate, thus leading to an equivalent single input, single output (SISO) system. The comparison of the resulting system with the classical first order systems typically utilized to model hydraulic canals shows that the proposed model has significantly lower error: about 50\%, and, therefore, higher accuracy in capturing the canal dynamics. This model has also been utilized to optimize the design of the controller of the pump of the canal, thus achieving a faster response to step commands and thus minimizing the interaction between the two pools of the experimental platform.
\end{abstract}

Keywords: hydraulic canal prototype; TITO fractional-order mathematical model; model validation; canal control

\section{Introduction}

The scarcity of fresh water has become a progressively-growing problem worldwide [1]. Water usage has grown by more than twice the rate of the world population increase during the last century, causing frequent conflicts between different users [2]. Water use by agriculture sector represents approximately $70 \%$ of all available freshwater on our planet [3], and irrigation has been classified as one of the activities that requires the largest volume of fresh water in the world [1,4]. At the same time, irrigation contributes to about $40 \%$ of the total food production, and it is a vital activity in many regions of the world [2]. However, in the near future, it is predicted that there will be less available water for irrigation due to competition with the industrial and domestic sectors [5]. At the same time, it will be necessary to increase food production to feed the growing world population [3]. The world's population is expected to grow to almost 10 billion by 2050 [2]. Therefore, with less available water for irrigation, a growing population, and the negative impacts of intensifying climate change, the agriculture sector will face enormous challenges, consisting of producing more food with less water [2]. One way to meet these challenges is to reduce the user's water demand by improving the hydraulic efficiency of irrigation systems [6]. Consequently, the studies related with the accurate 
management of available water resources in irrigation systems have a high economic, social, and strategic interest $[7,8]$.

Currently, a major part of the 250 million ha irrigated worldwide is served by surface canal systems. In many cases, their performance is lower than mediocre [9]. There is a critical need for improvements in terms of water resource management, efficiency of main irrigation canals, service to irrigated agriculture, and cost effectiveness of infrastructure management $[9,10]$.

The main irrigation canals are inherently complex and exhibit great variability of their dynamic parameters over a range of temporal and spatial scales [1,6]. Knowing, understanding, and predicting this variability is essential for the design of effective and robust controllers of this class of dynamic systems. The entropy may help to determine the variability range of the dynamic parameters of these hydraulics systems and the scales in which the organization of these systems occurs. Recently, information entropy has been applied in irrigation canals $[5,11,12]$. As main irrigation canals become more complex, entropy theory enables hydraulic and control engineers to quantify uncertainties, determine risk and reliability, estimate parameters, model processes, and design more robust and reliable hydraulic canals control systems.

Automation in canal irrigation delivery systems has been demonstrated to increase the global hydraulic efficiency of the irrigation main canals, from less than $40 \%$ for traditional irrigation canals, up to more than $90 \%$ for modern canals equipped with automatic control systems [1,13-15]. Automation also enables an improvement in the quality of the water delivery service to users and safeguards the canal infrastructures during emergencies, such as strong rainstorms or technical failures [9].

Nowadays, many of the new irrigation main canals have been designed and built, using modern technologies with advanced control systems [10]. Still, more than $90 \%$ of the irrigation canals worldwide continue to use traditional technologies and manual operation principles [14]. Some reasons are the lack of operators trained in the modern technologies and the unwillingness of the irrigation systems managers to change to unknown systems with new equipment and new operation and maintenance methods [9]. Despite of the changing technological context of the irrigation systems, the operators of these systems continue to be trained in the same traditional way that only prepares them to maintain hydraulic infrastructures and not to control and manage these systems in effective ways $[9,14]$.

Therefore, the development of the prototype laboratory hydraulic canals equipped with flexible electronic platforms of automatic controllers for the training of operators and engineers in the new technologies of control and management of irrigation systems has a high scientific-technical interest.

Currently, different companies in the world offer these types of hydraulic laboratory canals conformed by a small upstream reservoir and a downstream canal pool, but without automatic control due to the complex and rapid dynamic behavior that these canal present. Consequently, the design of effective and robust control systems for this class of laboratory-scale prototype canals constitutes an open research problem.

However, the design and implementation of control systems of irrigation canals need mathematical models that accurately describe their dynamic behavior under realistic conditions [1,7,16,17]. Mathematical models have also been used to understand the hydraulic behavior of complex and large irrigation networks, especially for evaluation and improvement of control system performance. However, it is well known that the achievement of these mathematical models is not a simple task $[1,15]$.

In order to obtain a mathematical model suitable for the control system design of irrigation main canals, two main methods have been proposed: the use of linearized Saint-Venant equations $[1,4]$ and the use of system identification approaches [18]. Currently, mathematical models based on system identification procedures are as accurate as models attained through Saint-Venant equations with estimated parameters, and they are easier to use [6].

A review of the main procedures used in the development of models for main irrigation canals was carried out in [19]. It includes: the Saint-Venant linearization model, an infinite order linear transfer function, a finite order non-linear model, a finite order linear state space model, a finite order 
linear transfer function, a neural network model, a fuzzy model, and a Petri net model. Some of the mathematical models of irrigation canals that have been proposed in the last decades are cited below.

An integrator with a delay model (ID) was obtained in [17] for a canal under backwater flow conditions. This model was also used to generate state-space MIMO (multiple input/multiple output) models of complete canals [20]. Some improvements to the ID model [17] were additionally proposed in [8]. Nonlinear irrigation canal models were developed in [21]. Some models of the water level evolution in an irrigation canal pool were proposed in [16]. These models were obtained based on a system identification approach, and they do not have any physical or hydraulic meaning. In addition, various SISO (simple-input/simple output) second-order models with dominant time delays of a main irrigation canal pool were obtained in [22-24] using different system identification procedures. However, the degree of adequacy of the cited models for the design of high performance control systems is not that required due to the nonlinear and distributed behavior of the canal, as well as to model parameter uncertainties, e.g., [6]. This means that there are still significant unsolved problems in this field.

In recent years, increasing attention has been paid to fractional-order calculus as a powerful tool with which to model and control a broad range of real industrial processes, e.g., [7,25-34]. In particular, fractional order differential equations are more adequate than integer-order equations when modeling certain processes in which distributed dynamics are dominant, as occurs in electrochemical processes [35,36], thermal processes [37,38], or hydraulic processes $[39,40]$.

Fractional-order models allows the design of fractional-order controllers that are more effective than traditional integer-order controllers (e.g., [39]). However, the problems related to developing useful MIMO fractional order-models, estimating their parameters, and using those in the control system design of irrigation canals have not been completely researched in the control literature.

This article proposes to increase the accuracy of the linearized models of canal pool dynamics by including fractional-order derivative operators. A TITO (two input/two output) fractional-order model of a canal with two pools is proposed, which has been derived based on a prototype laboratory hydraulic canal. This model is obtained by means of a direct system identification approach [41], which allows the immediate derivation of a continuous-time model using continuous-time model identification tools [42].

The combination of the TITO model and a control loop of the pump of the system to keep the upstream water level constant to mimic the experimental system allow to reproduce the experimental results with a higher fidelity (up to a 50\% of improvement) than the linearized MIMO models traditionally proposed in the literature. Additionally, the dynamics of the TITO system is utilized to propose a systematic methodology to design a proportional integral (PI) controller for the pump that outperforms the PID utilized experimentally, which was designed by trial and error.

\section{The Laboratory Prototype of the Hydraulic Canal}

The laboratory prototype of the hydraulic canal studied in this article is a variable slope rectangular water canal with glass walls and a methacrylate bottom located in the Fluid Mechanics Laboratory of the Castilla-La Mancha University (Spain). This canal is used in the training of operators and engineers in the new technologies of control and management of irrigation systems.

The canal is $5 \mathrm{~m}$ long and $8 \mathrm{~cm}$ wide, while its walls are $25 \mathrm{~cm}$ high. It consists of a closed-loop water canal with an instrumental platform that integrates electro-mechanical sensors and actuators, a PLC (programmable logic controller) SIMATIC S7-300 (SIEMENS, Germany), and a SCADA (data acquisition and supervisory system). The canal has motorized and manual adjustable slide gates that allow it to be divided into pools of different lengths. The current configuration of the canal is composed of two pools: the first one acting basically as a reservoir, and the second one acting as a main canal pool of approximately $4.7 \mathrm{~m}$ in length with a downstream end operation (delivering the required water flow at its downstream end). The upstream gate of this main pool is a motorized undershot 
gate, which connects the two pools, and the downstream gate is a manually-adjustable overshot gate. A schematic representation of this laboratory prototype of the hydraulic canal is shown in Figure 1.

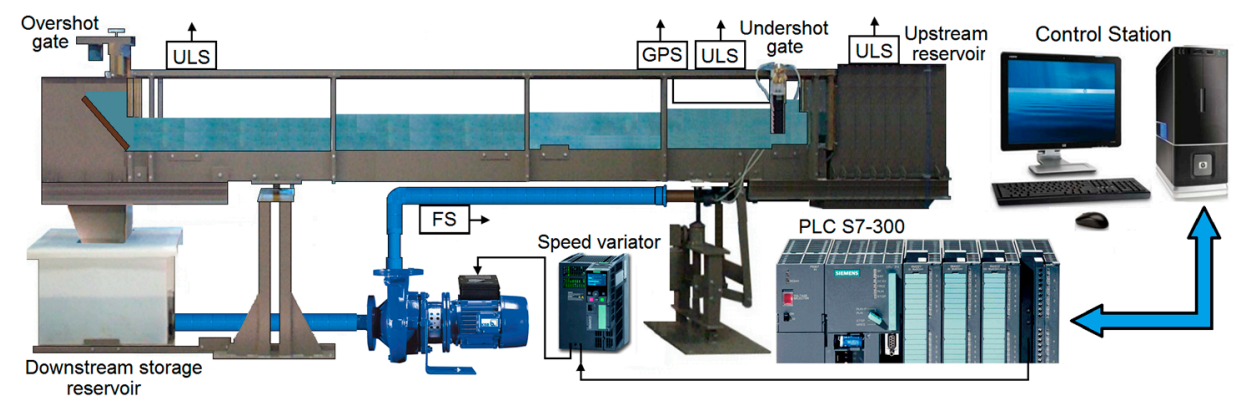

Figure 1. Schematic representation of the laboratory prototype of the hydraulic canal under study.

The water flows in a closed circuit from an upstream reservoir to a downstream storage reservoir in order to avoid water losses. The return of the water to the upstream reservoir is guaranteed by an electric motor-pump. This motor-pump operates with a speed variator, thus allowing adjustments in frequency from 0 to $50 \mathrm{~Hz}$. The total canal inflow is adjustable from 0 to $9 \mathrm{~m}^{3} / \mathrm{h}(\approx 2.5 \mathrm{~L} / \mathrm{s})$. The laboratory canal has a water extraction system with which to simulate user's water offtakes. Two ultrasonic level sensors (ULS), positioned outside the top of the canal, are used to monitor and control the upstream and downstream water levels. A third ultrasonic sensor measures the downstream end water level. The motorized slide undershot gate is equipped with a DC motor and a gate position sensor (GPS). The canal is also equipped with a flowmeter (FS), which is located in the water return tube and measures the canal water inflow pumped by the motor-pump from the downstream storage reservoir toward the upstream reservoir. This canal is also equipped with a PC (personal computer), which is used as a canal control station. A SCADA application is installed on this PC to guarantee the supervision of the canal.

\section{TITO Models}

As it was mentioned in the previous section, the inputs to our experimental system are the control signal of the pump $\left(u_{1}\right)$ given in $\mathrm{Hz}$, and the control signal for the actuator of the upstream gate opening $\left(u_{2}\right)$ in $\mathrm{mm}$. The outputs of this system are the water levels of the two pools of our canal ( $y_{u p}$ for the reservoir pool and $y_{d w e}$ for the main canal pool).

These two inputs and outputs define a TITO system where the behavior of the system is highly nonlinear and depends on the operating regime. To obtain a linearized model of our system, the operating regime is defined by a pump control value $u_{10}=19.5 \mathrm{~Hz}$ (a flow of $3.25 \mathrm{~m}^{3} / \mathrm{h}$ ) and an upstream gate opening $u_{20}=35 \mathrm{~mm}$. From now on, incremental variables around this operating point will be used, which will be represented by adding the increment symbol to the name of the variable.

We are interested in assessing if fractional-order models can improve the description of our canal dynamics provided by integer order models. We mention, that the identification of the fractional order dynamics of a system can be obtained from either its frequency response [35] or its time response to step or pulse inputs [36]. In this work, models will be fitted to time responses and step inputs.

\subsection{Identified Models}

Several models of the incremental linearized $2 \times 2$ TITO were obtained in [43]. In particular, a standard multivariable model based on integer order transfer functions with a delay of the form:

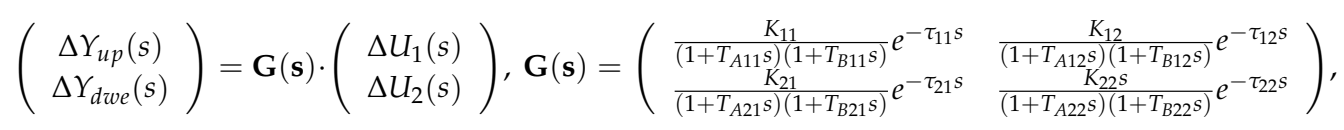


and a multivariable model based on fractional-order transfer functions with a delay of the form:

$$
\left(\begin{array}{c}
\Delta Y_{u p}(s) \\
\Delta Y_{d w e}(s)
\end{array}\right)=\mathbf{G}(\mathbf{s}) \cdot\left(\begin{array}{c}
\Delta U_{1}(s) \\
\Delta U_{2}(s)
\end{array}\right), \mathbf{G}(\mathbf{s})=\left(\begin{array}{cc}
\frac{K_{11}}{1+T_{11} s^{\alpha_{11}}} e^{-\tau_{11} s} & \frac{K_{12}}{1+T_{12} s^{\alpha_{12}}} e^{-\tau_{12} s} \\
\frac{K_{21}}{1+T_{21} s^{\alpha_{21}}} e^{-\tau_{21} s} & \frac{K_{22} s_{22}}{1+T_{22} s^{s_{22}}} e^{-\tau_{22} s}
\end{array}\right)
$$

were experimentally obtained. Let us here denote the element of the i row and the $j$ column of matrix $\mathbf{G}(\mathrm{s})$ as $G_{\mathrm{ij}}(s)$.

In both cases, in order to estimate the parameters of the transfer functions that compose the matrices $\mathbf{G}(\mathrm{s})$, a normalization of the integral square error (ISE) index was utilized to measure the fitting between the experimental results and the ones produced by simulating the models. Equation (1) is often used in practice, and its transfer functions have only four parameters to be identified $\left(K_{\mathrm{ij}}, T_{\mathrm{Aij}}\right.$ $T_{\mathrm{Bij}}$, and $\tau_{\mathrm{ij}}$. The estimated values of the parameters of these models are shown in Table 1.

Table 1. Parameters of the integer order models fitted to the experimental responses.

\begin{tabular}{ccccc}
\hline Index & $\boldsymbol{K}_{\mathrm{ij}}$ & $\boldsymbol{T}_{\boldsymbol{A} \mathrm{ij}}$ & $\boldsymbol{T}_{\boldsymbol{B} \mathrm{ij}}$ & $\boldsymbol{\sigma}_{\mathrm{ij}}$ \\
\hline 11 & 2.056 & 5.041 & 0 & 1.05 \\
\hline 12 & -0.3563 & 2.572 & 0 & 0.45 \\
\hline 21 & 0.8653 & 4.798 & 0 & 5.4 \\
\hline 22 & 0.500 & 1.86 & 1.86 & 4.05 \\
\hline
\end{tabular}

Equation (2) is more complex as it presents one additional parameter in each of its transfer functions-the fractional-order $\alpha_{i j}$-with the exception of $G_{22}(s)$ that also presents the parameter $\beta_{22}$. However, this model captures the dynamics of the system with greater accuracy, as can be seen from the percentage of improvement shown in Table 2.

Table 2. Parameters of the fractional order models fitted to the experimental response.

\begin{tabular}{ccccccc}
\hline Index & $\boldsymbol{K}_{\mathrm{ij}}$ & $\boldsymbol{T}_{\mathrm{ij}}$ & $\boldsymbol{\sigma}_{\mathrm{ij}}$ & $\mathbf{f f}_{\mathbf{i j}}$ & $\mathbf{f}_{\mathbf{i j}}$ & Percentage of Improvement $(\%)$ \\
\hline 11 & 2.056 & 4.0 & 1.05 & 0.91 & - & 45 \\
\hline 12 & -0.3563 & 2.7 & 0.45 & 1.03 & - & 1.4 \\
\hline 21 & 0.8653 & 3.7 & 5.4 & 0.89 & - & 33.3 \\
\hline 22 & 0.291 & 1.5 & 4.05 & 1.1 & 0.88 & 41.03 \\
\hline
\end{tabular}

All the previous values were obtained in [43], and demonstrate that there is an important improvement in the agreement between the experimental data and the simulated results when the fractional order transfer functions are employed in the TITO system in order to reproduce the experimental results. There is only one exception: the case of the transfer function $G_{12}$ in which the improvement is nearly negligible.

\subsection{Controlling the Water Level of the First Pool}

As it was stated in the previous section, in order to avoid water loses, the water flows in a closed circuit from an upstream reservoir to a downstream storage reservoir. However, the dimensions of that upstream reservoir are relatively small. In order to emulate with this reservoir a pool of a canal with a very large amount of water, in which the water level $y_{u p}$ remains approximately constant in spite of the pool water being discharged to the following pool through a gate, the water level of this reservoir is controlled by closing a loop in which the pump is the input (the input signal is $u_{1}$ ).

With the purpose of reproducing real-world conditions, in which the water level of the first pool is not dependent on the opening of the upstream gate, it is very important to optimize the performance of the above-mentioned control loop of the first pool. It intends to quickly remove any variation of the water level of this pool caused by the opening of the gate. 
Typically, a proportional integral derivative (PID) regulator is utilized to overcome the issues produced by the small dimensions of the upstream reservoir [44]. Figure 2 shows a PID scheme, where $K_{P}$ and $K_{i}$ are the proportional and integral gains respectively, and they are set to $K_{P}=0.2$, $K_{i}=0.08$, and $K_{d}=0.02$, and the parameter $\mu=0.01$ is chosen small enough to not noticeably modify the dynamics of the regulator and make it implementable. As a consequence of closing this feedback loop, our original TITO system is transformed into a SISO system whose single input is $\Delta U_{2}$ (s) (the other input $\Delta U_{1}(\mathrm{~s})$ has been substituted by a constant reference $\Delta Y_{u p}^{*}(\mathrm{~s})$ which becomes a null input in the linearized model) and a single output $\Delta Y_{u p}(s)$.

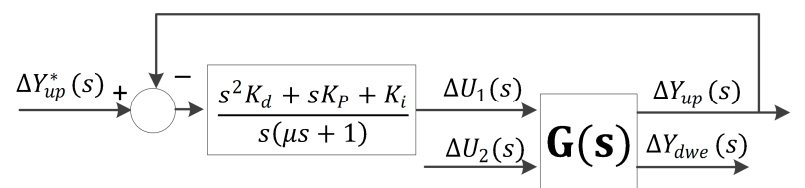

Figure 2. Control scheme of the first pool.

Once the PID controller that keeps the upstream water level in a fixed reference has been designed, several maneuvers were performed by the upstream gate to identify the remaining dynamics basically associated to the second pool. The upstream reference is kept equal to $60 \mathrm{~mm}$ and 12 steps of different amplitudes were applied to the opening of the gate. The amplitude of these steps and the variations of the downstream level are depicted in Figure 3.
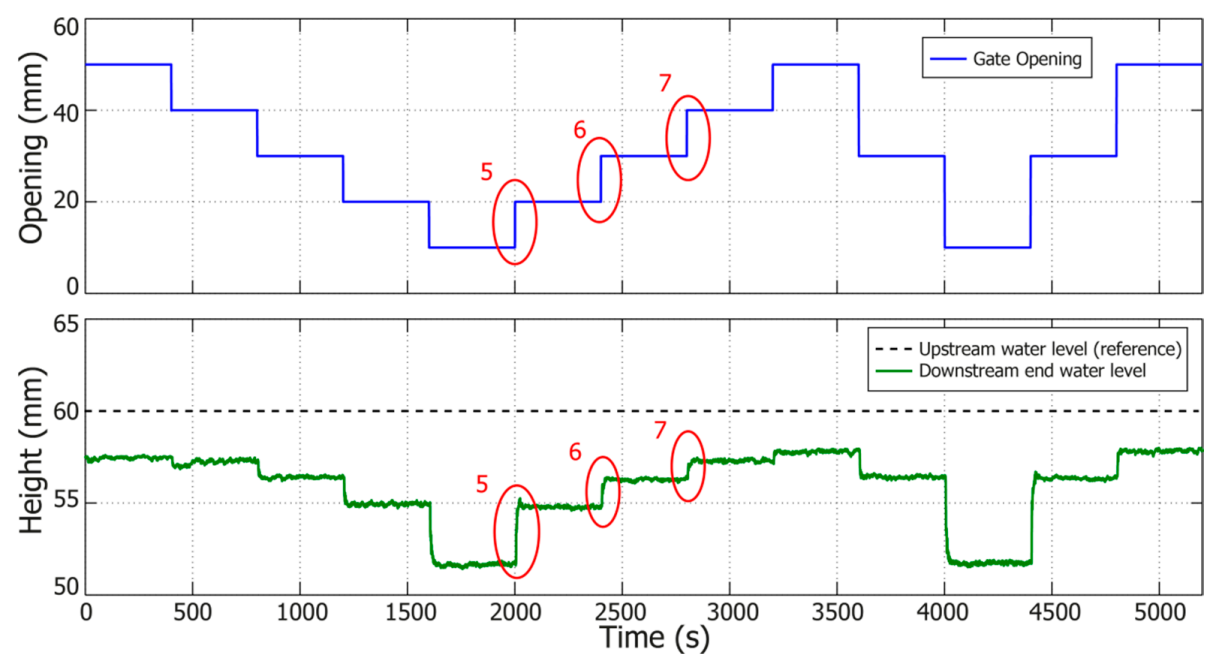

Figure 3. Upstream gate opening maneuvers and downstream end water level responses.

From the experimental data obtained in [44] it was observed that the dynamic response of the system presents a strong dependence with the operating point of the system and, thus, different behaviors can be obtained depending on the opening of the gate. The most representative examples of these different dynamics are the responses to steps 5-7 (encircled in Figure 3).

To analyze the fitting between the experimental responses in these cases and the identified models of these responses we have to define the fitting index $E$ as follows:

$$
E=\sqrt{\frac{1}{t_{f}} \int_{0}^{t_{f}}\left(\frac{\Delta y_{e}(t)}{\Delta y_{s}}-\frac{\Delta y_{m}(t)}{\Delta y_{s}}\right)^{2} d t},
$$

where $\Delta y_{e}(t)$ is the incremental experimental response, $\Delta y_{m}(t)$ is the response provided by the proposed model, $t_{f}$ is the duration of the experimental data $\left(t_{f}=40\right)$, and $\Delta y_{s}$ is the steady state value of the experimental data. 
Once steps 5-7 have been analyzed, three different behaviors are observed:

(1) The dynamics of step 5 are close to an integer first-order plus time delay system. Figure 4 shows the experimental response and the simulated response of the system:

$$
G_{11,1}(s)=\frac{0.1056}{s+0.33} e^{-5 s},
$$

which has been fitted to the experimental data by minimizing Equation (3). The fitting index obtained is $E=0.057$.

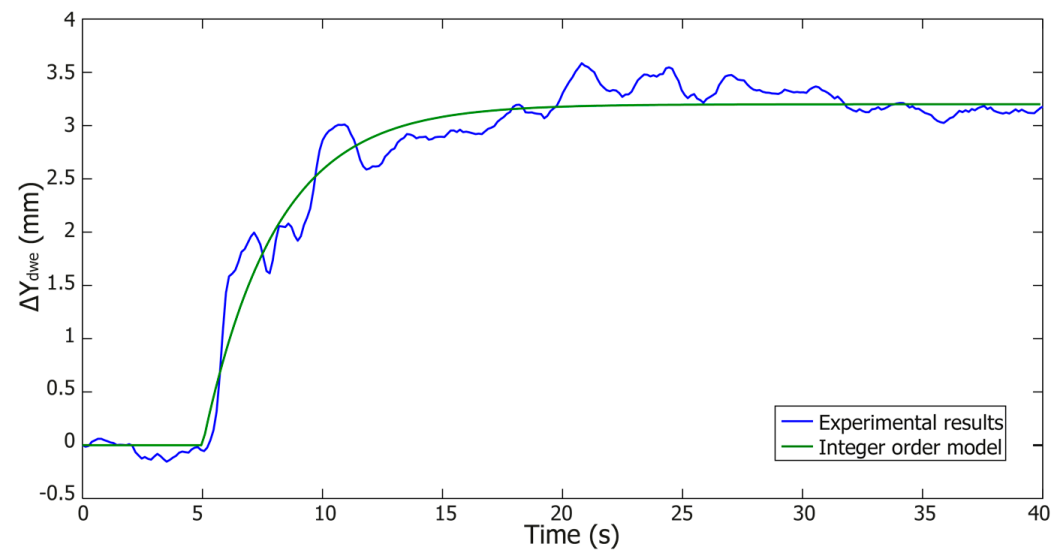

Figure 4. Fitting of an integer first-order plus time delay system to the experimental water level response of the second pool to step 5 in the gate opening $u_{2}(t)$.

(2) The dynamics of step 6 are close to a fractional-order plus time delay system. Figure 5 shows the experimental response and the simulated responses of the systems:

$$
G_{11,1}(s)=\frac{0.03255}{s+0.35} e^{-5 s}, G_{11,2}(s)=\frac{0.0534}{s^{0.85}+0.59} e^{-5 s},
$$

which have also been fitted to the experimental data by minimizing Equation (3). The fitting indices obtained for $G_{11,1}(s)$ and $G_{11,2}(s)$ are $E=0.092$ and $E=0.090$, respectively. These values and Figure 5 show that, in this case, the experimental response cannot be accurately fitted by an integer order plus time delay model. A fractional order plus time delay model slightly improves this fitting, however, it still does not reproduce an oscillation that appears at the beginning of the response when it is rising.

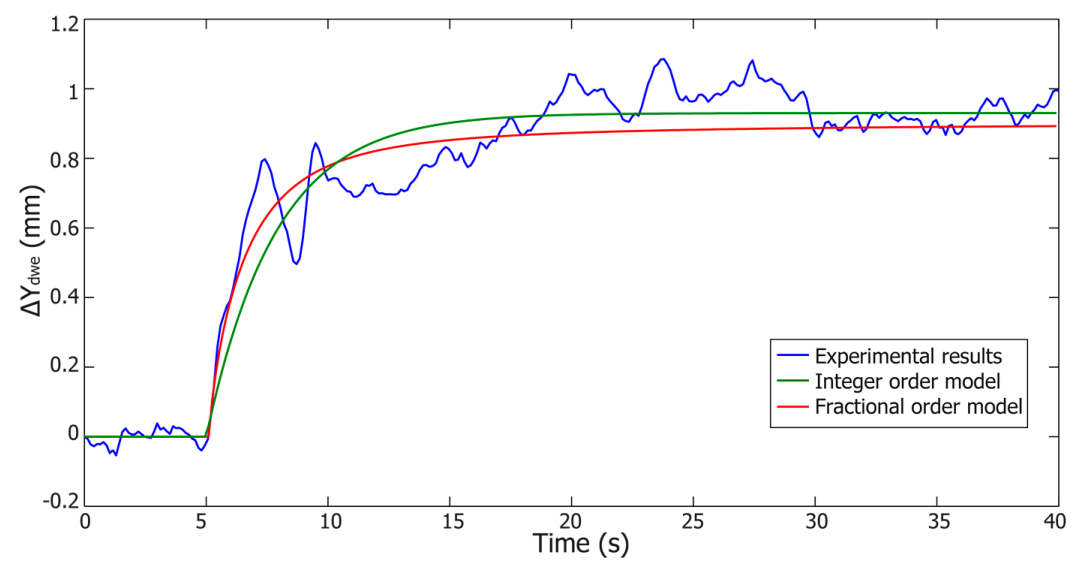

Figure 5. Fitting of a fractional-order plus time delay system to the experimental water level response of the second pool to step 6 in the gate opening $u_{2}(t)$. 
(3) The dynamics of step 7, which show a behavior with a complex transient response that cannot be accurately described by any of the previous models. Figure 6 shows the experimental response and the simulated responses of some models with different structures:

$$
\begin{gathered}
G_{11,1}(s)=\frac{0.0435}{s+0.3} e^{-5 s}, G_{11,2}(s)=\frac{0.093}{s^{0.73}+0.63} e^{-5 s}, \\
G_{11,3}(s)=\frac{0.0522(s+0.5)}{s+0.18} e^{-5 s}, G_{11,4}(s)=\frac{0.7772}{(s+0.29)(s+18.4)} e^{-5 s}, \\
G_{11,5}(s)=\frac{2.827442}{(s+0.29)\left(s^{2}+67.24\right)} e^{-5 s},
\end{gathered}
$$

whose parameters have been fitted to the experimental data by minimizing Equation (3). The fitting indices obtained for $G_{11,1}(s), G_{11,2}(s), G_{11,3}(s), G_{11,4}(s)$, and $G_{11,5}(s)$ are $E=0.1698, E=0.1437$, $E=0.1332, E=0.1698$, and $E=0.1697$, respectively. These values and Figure 6 show that, in this case, the experimental response cannot be fitted, neither by the integer-order nor the fractional-order plus time delay models, or by higher-order SISO models. The oscillation that appears at the beginning of the response is in this case more significant than in the previous case, and prevents the accurate fitting of any of these models.

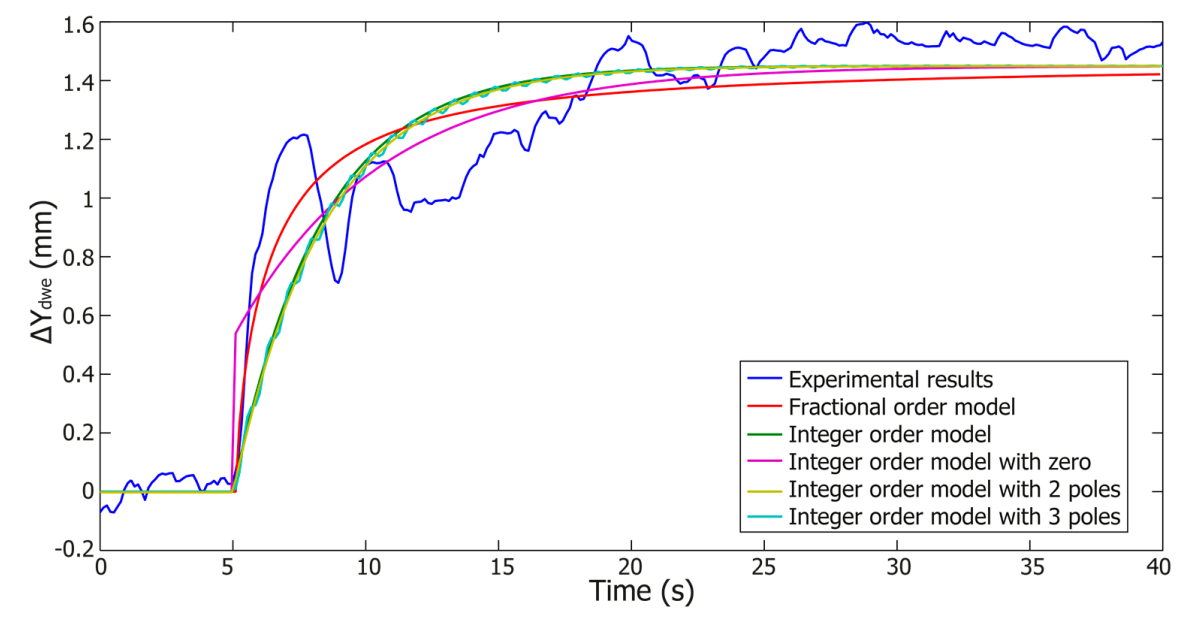

Figure 6. Fitting of the previous models to the experimental water level response of the second pool to step 7 in the gate opening $u_{2}(t)$.

\section{Obtaining an Accurate Theoretical Model of the Complex Transient Response of the Canal}

As it has been showed in the previous section, there are several steps like step 7 that present a transient response with complex dynamics that cannot be captured by neither using a classical first order system plus time delay nor a simple fractional-order system plus time delay. In order to develop a more accurate model, we utilize the TITO model and obtain the equivalent transfer function obtained after closing the loop of the pump of the canal.

If we denote the PID regulator as R(s), according to the control scheme showed in Figure 2, the incremental input signal to the pump is:

$$
\Delta \mathrm{U}_{1}(s)=\left(\Delta Y_{u p}^{*}(s)-\Delta Y_{u p}(s)\right) \cdot R(s) .
$$

Substituting Equation (7) in the TITO model given by Equation (1) or (2), and assuming a constant reference of the upstream water level is set $\left(\Delta Y_{u p}^{*}(s)=0\right)$, the TITO system can be expressed as:

$$
\left(\begin{array}{c}
\Delta Y_{u p}(s) \\
\Delta Y_{d w e}(s)
\end{array}\right)=\left(\begin{array}{ll}
G_{11}(s) & G_{12}(s) \\
G_{21}(s) & G_{22}(s)
\end{array}\right) \cdot\left(\begin{array}{c}
-R(s) \cdot \Delta Y_{u p}(s) \\
\Delta U_{2}(s)
\end{array}\right) .
$$


Operating this expression yields:

$$
\Delta Y_{u p}(s)=\frac{G_{12}(s) \Delta U_{2}(s)}{1+G_{11}(s) R(s)}
$$

and, thus, the TITO model can be reduced to a SISO model that relates the water level at the end of the second pool with the opening of the gate as follows:

$$
\frac{\Delta Y_{\text {dwe }}(s)}{\Delta U_{2}(s)}=\frac{G_{22}(s)+\left(G_{11}(s) \cdot G_{22}(s)-G_{21}(s) \cdot G_{22}(s)\right) R(s)}{1+G_{11}(s) R(s)} .
$$

Subsequently, we assess if this model can potentially capture the recorded experimental dynamics better than the models presented in Section 3.2, i.e., if the dynamics described in Figure 6 can be better fitted by Equation (10). We consider two cases in our study: (1) utilizing the transfer functions given by the integer-order TITO model (Equation (1)) with the parameters of Table 1 and (2) utilizing the transfer functions given by the fractional-order TITO model (Equation (2)) with the parameters of Table 2.

The identification methodology used in Section 3.2 implies that the values of all the parameters of the model are obtained from an optimization procedure that minimizes the ISE index (Equation (3)). However, Equation (10) has too many parameters to be tuned (20 parameters). We have made the decision of tuning only three parameters of the transfer function (Equation (10)) and maintain the 17 remaining parameters in the values identified in [43] (values given in Table 1 for the integer-order model and in Table 2 for the fractional-order model). Figure 7 shows the experimental response and the simulated responses obtained after tuning these three parameters in the transfer functions (Equation (10)) in the cases of using the integer-order and the fractional-order TITO models.

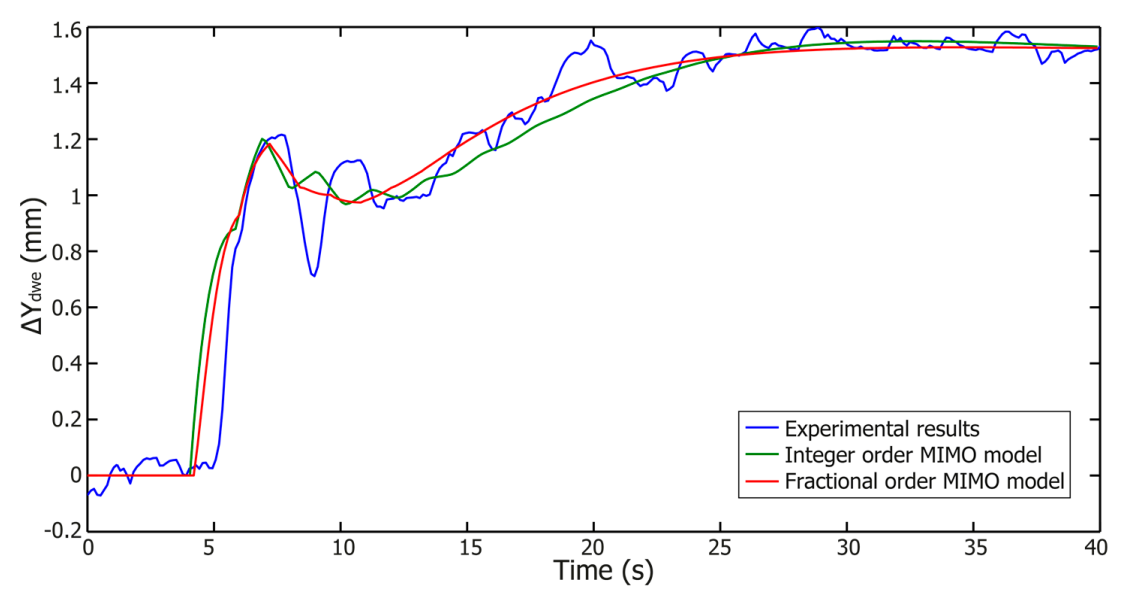

Figure 7. Fitting of the water level response of the second pool to a step in the gate opening $u_{2}(t)$ to integer-order and fractional-order TITO systems.

It can be seen in this figure that the fractional-order fitting reproduces the experimental dynamics with better accuracy (which is a foreseeable result, since the fractional model presented a great improvement compared to the integer-order model as seen in Table 2). The obtained values of the fitting index for the integer order and the fractional order models are $E=0.087$ and $E=0.066$, respectively. There is a percentage of improvement equal to $24.1 \%$ when the integer order and fractional order are compared. On the other hand, it is important to note that if we compare the fitting index produced by the fractional version of this model $(E=0.066)$ and the best result produced by the fitting of a SISO system in the previous section $G_{11,3}(s)$ (which yielded a fitting index $E=0.1332$ ), an improvement equal to $50.5 \%$ is obtained if the proposed fractional TITO model is utilized to reproduce the experimental response. 
Additionally, in order to illustrate the flexibility of the proposed TITO model (Equation (2)), this model was also identified in the operating points that correspond to the steps 5 and 6 , and then the experimental responses corresponding to these steps were fitted by following the aforementioned procedure. The numerical values obtained in each operating point are showed in Table 3.

Table 3. Parameters of the fractional order models fitted to the operating points of steps 5 and 6 .

\begin{tabular}{ccccccc}
\hline Index & $\boldsymbol{K}_{\mathbf{i j}}$ & $\boldsymbol{T}_{\mathbf{i j}}$ & $\mathbf{\sigma}_{\mathbf{i j}}$ & $\mathbf{f f}_{\mathbf{i j}}$ & $\mathbf{f i}_{\mathbf{i j}}$ & Operating Point \\
\hline 11 & 1.9 & 14 & 1.05 & 1.1 & - & Step 5 \\
12 & -0.1 & 0.1 & 0.45 & 1.7 & - & Step 5 \\
21 & 5.8 & 22 & 5.4 & 1.1 & - & Step 5 \\
22 & 3 & 10 & 4.05 & 1.2 & 1.2 & Step 5 \\
11 & 4.1 & 6 & 1.05 & 0.90 & - & Step 6 \\
12 & -0.3 & 8 & 0.45 & 0.9 & - & Step 6 \\
21 & 2 & 2 & 5.4 & 0.9 & - & Step 6 \\
22 & 1.2 & 10 & 4.05 & 0.9 & 1 & Step 6 \\
\hline
\end{tabular}

Once the TITO models for the different operating points are obtained we can reproduce the experimental responses with a great accuracy as it can be seen in Figures 8 and 9. In these cases the fitting indexes were $E=0.055$ for the step 5 and $E=0.094$ for the step 6 . If we compare these results with the best fittings produced by the SISO systems in these operating points ( $E=0.057$ for the step 5 and $E=0.090$ for step 6), we can see that the results obtained using TITO models and SISO models are very close. This can be justified because these experimental responses of the system are very smooth and do not present complex transient responses, which are the cases in which the advantages of the TITO model may be fully exploited.

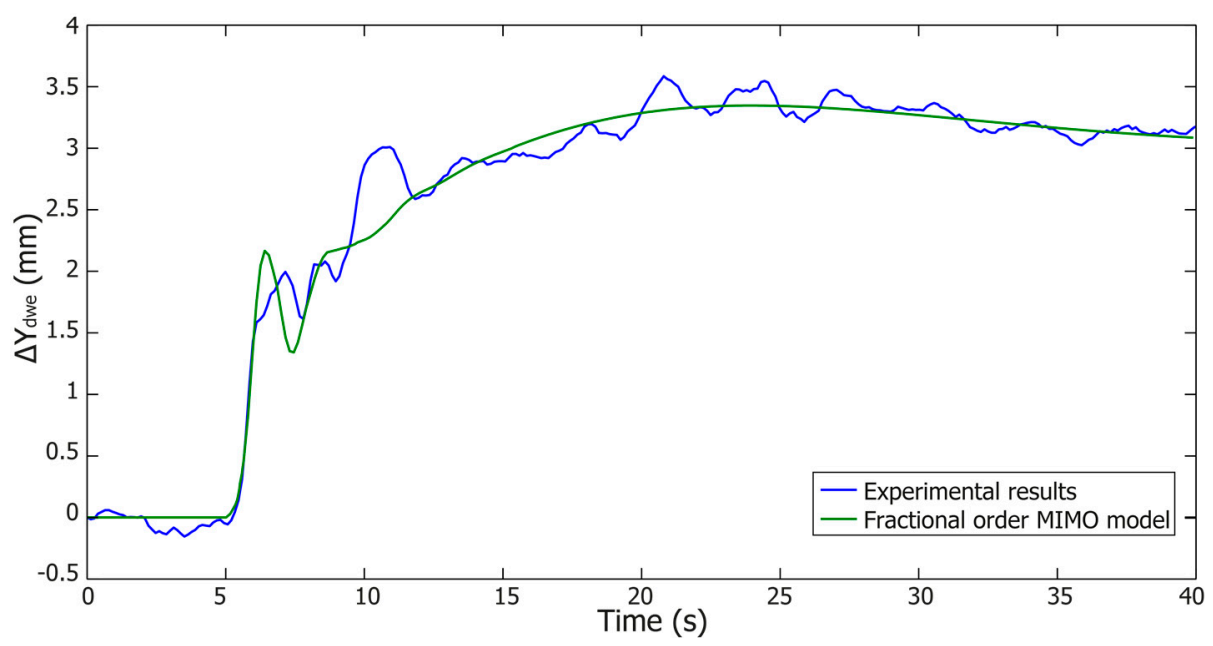

Figure 8. Fitting of a fractional order TITO systems to the experimental water level response of the second pool to step 5 in the gate opening $u_{2}(t)$.

The transfer function of the resulting fractional order fitted model can be obtained if we substitute the values of Equation (2) into Equation (10), leading to the following expression:

$$
\begin{aligned}
& \frac{\Delta Y_{\text {dwee }}(s)}{\Delta U_{2}(s)} \\
& =\frac{\frac{K_{22} \beta_{22}}{1+T_{22} s^{\alpha_{22}}} e^{-\tau_{22} s}+\left(\begin{array}{c}
\frac{K_{11}}{1+T_{11} s^{\alpha_{11}}} \frac{K_{22} s_{22}}{1+T_{22} s^{\alpha_{22}}} e^{-s\left(\tau_{22}+\tau_{11}\right)}- \\
\frac{K_{12}}{1+T_{12} s^{\alpha_{12}}} \frac{K_{21}}{1+T_{21} s^{\alpha_{21}}} e^{-s\left(\tau_{12}+\tau_{21}\right)}
\end{array}\right) \frac{K_{d} s^{2}+K_{p s} s+K_{i}}{s(\mu s+1)}}{1+\frac{K_{11}}{1+T_{11} s^{\alpha_{11}}} e^{-\tau_{11} s} \frac{K_{d} s^{2}+K p s+K_{i}}{s(\mu s+1)}} .
\end{aligned}
$$


This can be expressed as:

$$
\begin{aligned}
& \frac{\Delta Y_{\text {dwe }}(s)}{\Delta U_{2}(s)} \\
& =e^{-\tau_{22} s} \frac{\frac{K_{22} s^{\beta_{22}}}{1+T_{22} s^{s_{22}}}+\left(\begin{array}{c}
\frac{K_{11}}{1+T_{11} s^{\alpha_{11}}} \frac{K_{22} s^{\beta_{22}}}{1+T_{22} s^{s_{22}}} e^{-s \tau 11}- \\
\frac{K_{12}}{1+T_{12} s^{\alpha_{12}}} \frac{K_{21}}{1+T_{21} s^{\alpha_{21}}} e^{-s\left(\tau_{12}+\tau_{21}-\tau_{22}\right)}
\end{array}\right) \frac{K_{d} s^{2}+K_{p s+K}}{s(\mu s+1)}}{1+\frac{K_{11}}{1+T_{11} 1^{\alpha_{11}} e^{-\tau_{11} s} \frac{K_{d} s^{2}+K_{p s} s K_{i}}{s(\mu s+1)}}} .
\end{aligned}
$$

Since the values of delays $\tau_{11}$, and $\left(\tau_{12}+\tau_{21}-\tau_{22}\right)$ are very small when compared with $\tau_{22}$, we can utilize the first order Padé of the time delay to approximate their behaviour:

$$
e^{-\tau s} \approx \frac{-s+2 / \tau}{s+2 / \tau}
$$

We can compute an approximation of Equation (12) as follows:

$$
\begin{aligned}
& \frac{\Delta Y_{\text {dwe }}(s)}{\Delta U_{2}(s)} \\
& =e^{-\tau_{22} s} \frac{\frac{K_{22} s^{s}}{1+T_{22} s^{\alpha_{22}}}+\left(\begin{array}{c}
\frac{K_{11}}{1+T_{11} s^{\alpha_{11}}} \frac{K_{22} s \beta_{22}}{1+T_{22} s^{\alpha_{22}}}\left(\frac{-s+2 / \tau_{11}}{s+2 / \tau_{11}}\right)- \\
\frac{K_{12}}{1+T_{12} s^{\alpha_{12}}} \frac{K_{21}}{1+T_{21} s^{\alpha_{21}}}\left(\frac{-s+2 /\left(\tau_{12}+\tau_{21}-\tau_{22}\right)}{s+2 /\left(\tau_{12}+\tau_{21}-\tau_{22}\right)}\right)
\end{array}\right) \frac{K_{d} s^{2}+K_{p} s+K_{i}}{s(\mu s+1)}}{1+\frac{K_{11}}{1+T_{11} s^{\alpha_{11}}} \frac{K_{d^{s}} s^{2}+K_{p} s+K_{i}}{s(\mu s+1)}\left(\frac{-s+2 / \tau_{11}}{s+2 / \tau_{11}}\right)} .
\end{aligned}
$$

Equation (14) is a general expression that can be particularized to the integer-order TITO model by substituting the parameters of Table 1.

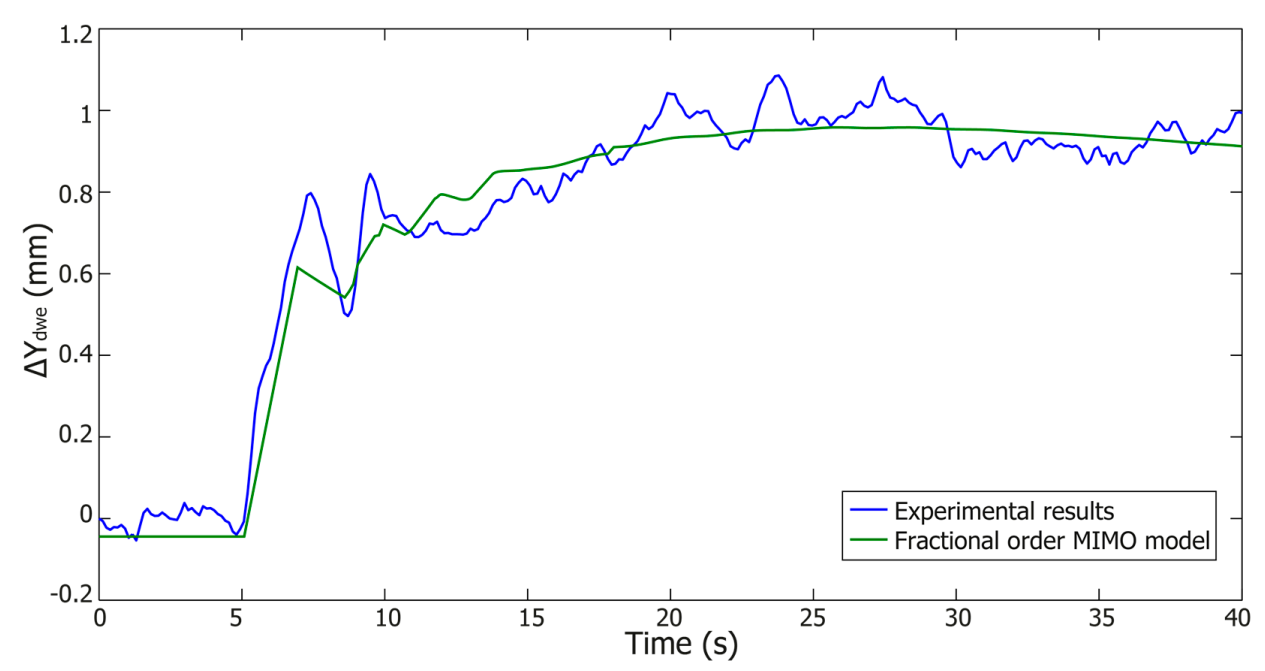

Figure 9. Fitting of a fractional order TITO systems to the experimental water level response of the second pool to step 5 in the gate opening $u_{2}(t)$.

\section{Improving the Control of the Water Level of the First Pool}

Usually, the parameters of the PID controller in charge of maintaining the water level of the first pool are tuned assuming that the system is characterized by only the transfer function $G_{11}(s)$ of $\mathbf{G}(s)$. Then the coupling existing between pools caused by the discharge of water from the first to the second pool through the upstream gate (which is represented by $G_{12}(s)$ in Equations (1) and (2)) is considered as an external disturbance.

The PID controller used in the previous sections was tuned by a trial and error procedure because in the past we did not have a reliable model of the process. Since a reasonably accurate model (Equation (2)) was obtained in [43], this section proposes to design an improved controller based on 
this model. Moreover, we will assess the impact produced on the controlled system performance by the fact of designing the controller using the integer-order TITO model (Equation (1)) or the fractional-order TITO model (2).

In order to maintain constant the water level of the first pool and remove any external perturbation as quickly as possible, it would be desirable to provide a simple way in which to tune its controller according to a minimum performance or robustness criteria. In [45] for example, a method with which to tune a robust distant downstream PI controller for an irrigation canal pool based on gain and phase margin requirements was developed. This section designs a PI controller for the first pool using a mix of frequency and time specifications.

In order to design the controller, the following specifications are proposed: (I) a desired phase margin $\varnothing_{m}$ which guarantees the desired nominal damping and robustness to changes in the delay; (II) a response with zero steady error to step changes in the set point as well as to step disturbances in the process input; and (III) a minimum settling time. Specification (II) is guaranteed by means of the integral term of the PI controller. Specification (I) can be expressed in a compact form by the complex equation:

$$
G_{11}\left(j \omega_{c}\right) \frac{K_{P}\left(j \omega_{c}\right)+K_{i}}{\left(j \omega_{c}\right)}=e^{j\left(-\left(\pi-\varnothing_{m}\right)\right)}=-e^{j \varnothing_{m}},
$$

where $\omega_{c}$ is the gain crossover frequency. Since the fractional order model $G_{11}(s)$ of Equation (2) is a generalization of the integer-order version given in Equation (1), substituting this into Equation (15) gives the complex design condition:

$$
\frac{\left(K_{P}\left(j \omega_{c}\right)+K_{i}\right)}{1+T_{1}\left(j \omega_{c}\right)^{\alpha}}=-\frac{\omega_{\mathcal{c}}}{K} e^{j\left(\varnothing_{m}+\omega_{c} \tau+\frac{\pi}{2}\right)},
$$

which is valid for both $G_{11}(s)$ transfer functions of Specifications (I) and (II). It can be seen in this expression that, for a given value of $\varnothing_{m}$ (which has a fairly standard value $\varnothing_{m}=60^{\circ}$ ), different pairs of parameters of the PI controller are obtained, depending on the value of $\omega_{c}$. In this design, $\omega_{c}$ was varied in the interval $[0,1] \mathrm{rad} / \mathrm{s}$. The relationship between the settling time and the gain crossover frequency $\omega_{c}$ for a fixed value $\varnothing_{m}=60^{\circ}$ was obtained for the two cases: the integer order and the fractional order transfer functions $G_{11}(s)$. These functions are plotted in Figure 10 and were used to design the PI controller that minimized the settling time, considered as the time required for the response curve to reach and stay within a range about the final value of size specified by a $5 \%$ of the final value.

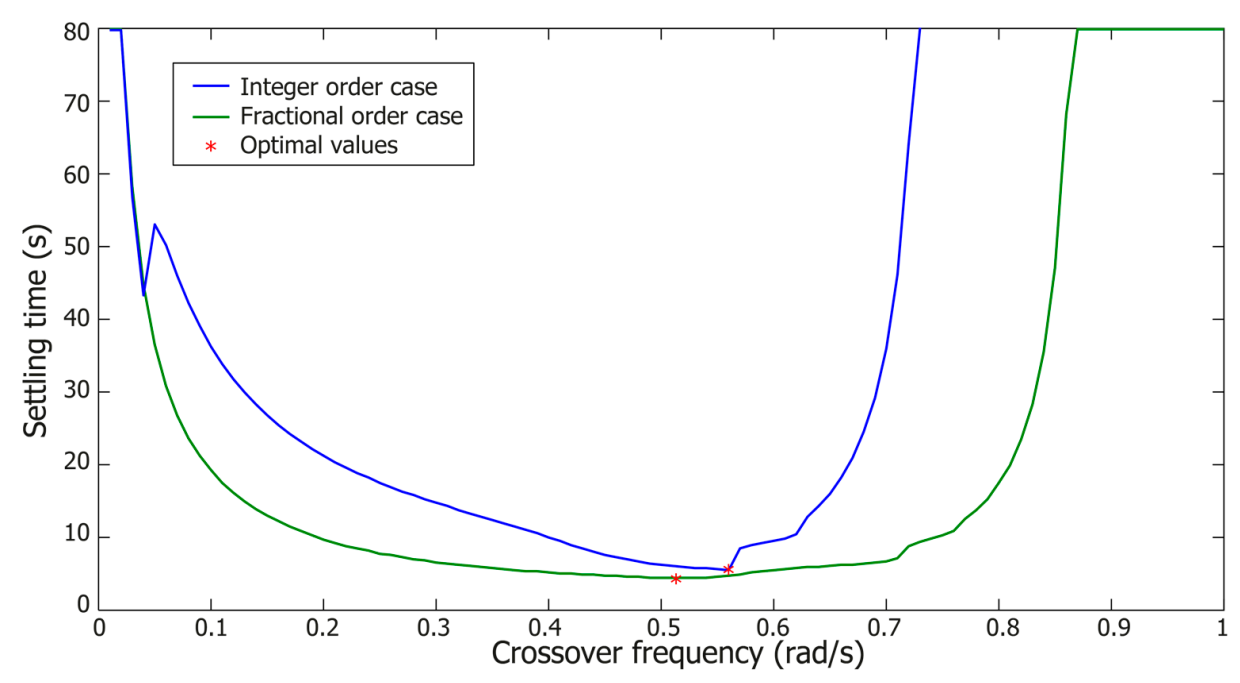

Figure 10. Dependency between the settling time and the gain crossover frequency. 
The controller that minimizes the settling time, obtained using the integer-order model, is:

$$
R(s)=\frac{1.401 s+0.2223}{s},
$$

and the controller that minimizes the settling time, obtained using the fractional-order model, is:

$$
R(s)=\frac{1.051 s+0.3175}{s},
$$

Figure 11 shows: (a) the simulated closed-loop responses of the fractional order model $G_{11}(s)$ to a unity step command when Equations (17) and (18) are used; and (b) the control signals applied to the pump by these regulators. It can be observed, comparing both responses, that Equation (17), i.e., the one designed based on the integer order model of $G_{11}(s)$, degrades its performance when it is faced to control the more accurate fractional-order model of the experimental platform (the settling time is larger than the value given by Figure 10). Additionally, it can be seen that the control signal applied to the pump has smaller amplitude with Equation (18), which means that a lower control effort is necessary to drive the pump.

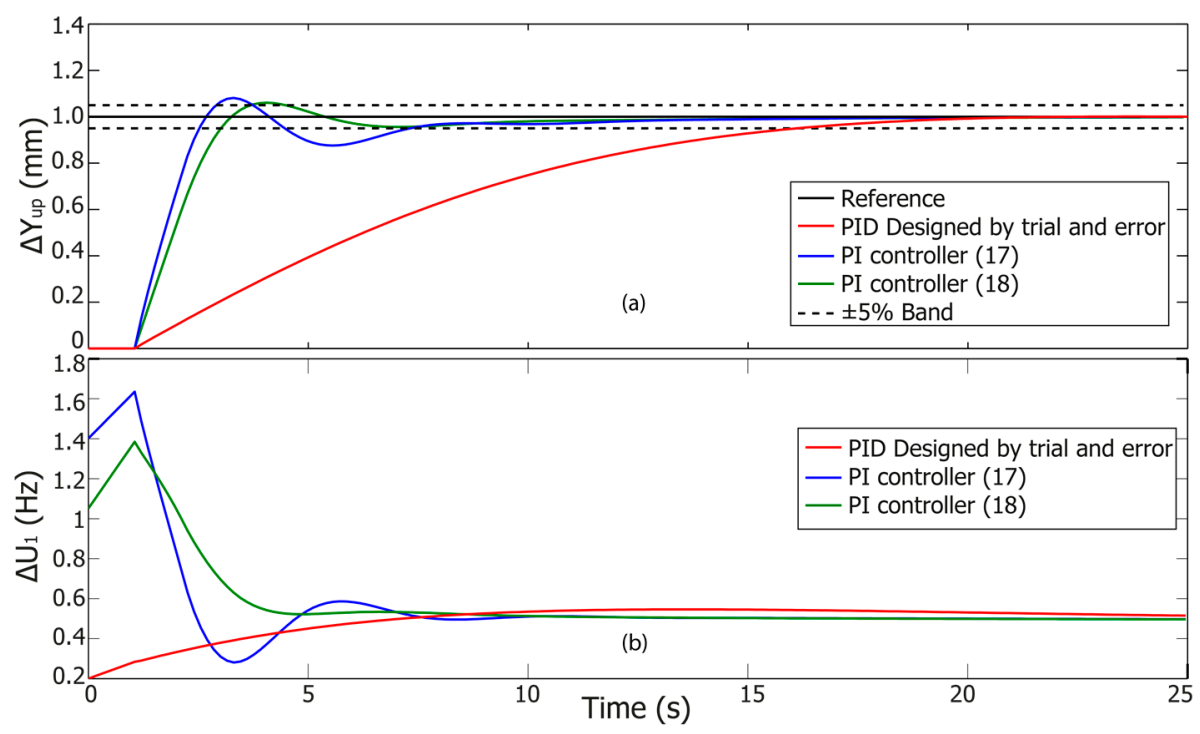

Figure 11. (a) Simulated time responses to step commands of the PI controllers designed by considering integer- and fractional-order models; (b) Control signals applied to the pump by the regulators.

Figure 11 also shows the simulated response of the fractional-order model $G_{11}(s)$ controlled with a PID designed by trial and error, based on the experience acquired by the operator when working with the experimental system. This result is included to illustrate that the performance of the system is dramatically improved when a systematic methodology based on a quantitative model of the process is employed to design the control scheme of the system.

Table 4 shows the numerical values of the settling time and the maximum peak achieved by the regulators whose responses were drawn in Figure 11. From these data it can be seen that the PI controller designed considering the fractional order model of the system has the lowest settling time, and thus the fastest response of all the cases, and it can also be seen that this model significantly outperforms the PID controller designed by trial and error. 
Table 4. Parameters of the time response of the PI and PID regulators to a unity step command.

\begin{tabular}{ccc}
\hline Case & Settling Time (s) & Peak Value (mm) \\
\hline Equation (17) applied to fractional-order system & 7.35 & 1.081 \\
Equation (18) applied to fractional-order system & 6.00 & 1.089 \\
Experimental PID applied to fractional-order system & 15.0 & 1.05 \\
\hline
\end{tabular}

The experimental validation of the results is showed in Figure 12, where the experimental responses of Equations (17) and (18) in the nominal conditions are compared with the simulated results. It can be seen that they reasonably reproduce the behavior obtained in simulation despite there being a significant noise in the experimental results.

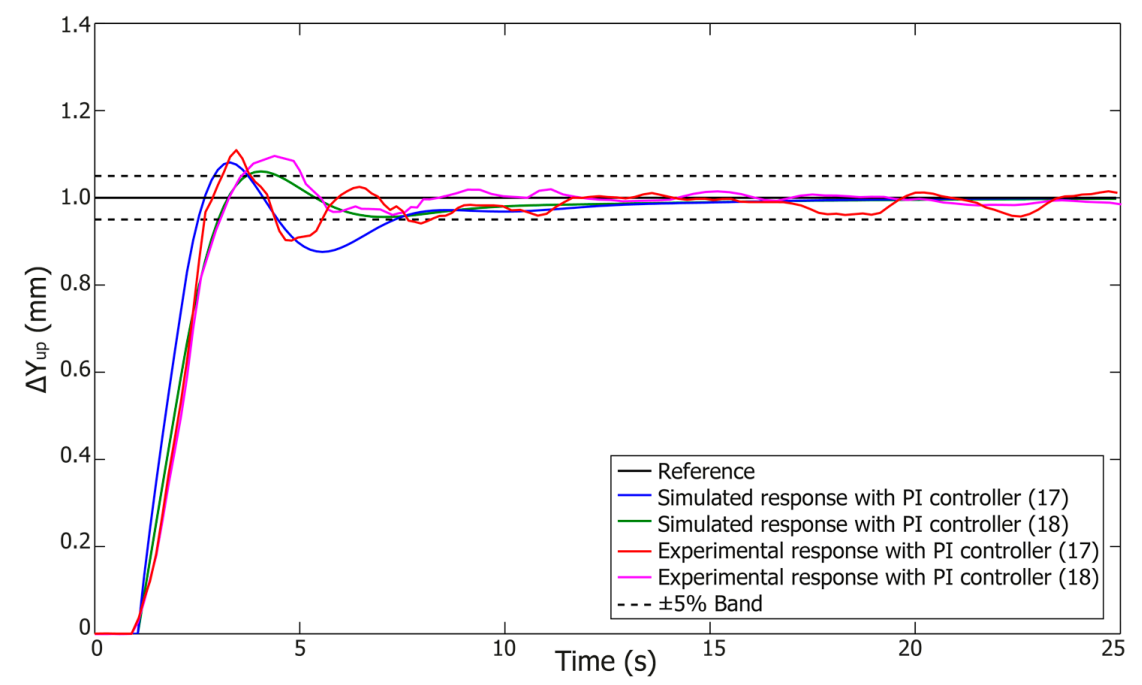

Figure 12. Experimental time responses to step commands of the PI controllers designed by considering integer- and fractional-order models.

Additionally, in order to evaluate the robustness of the proposed Equations (17) and (18), they were applied to different operating points, i.e., with gate openings of $10 \mathrm{~mm}$ and $30 \mathrm{~mm}$. The obtained results are shown in Figure 13.

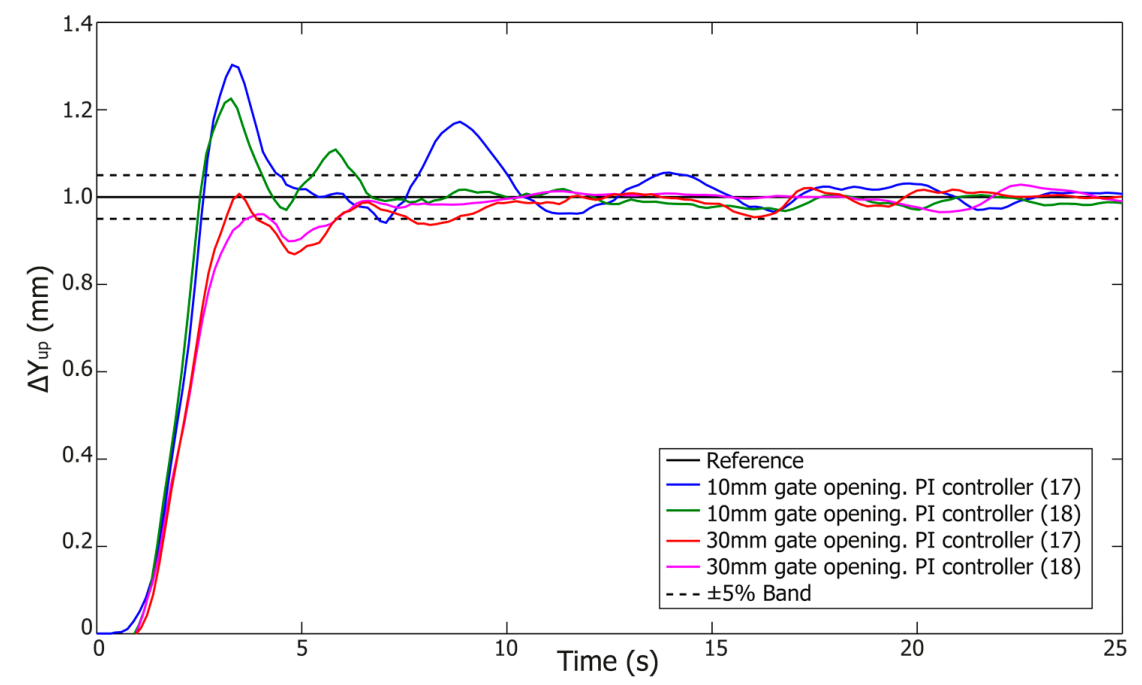

Figure 13. Experimental time responses to step commands of the PI controllers designed by considering integer- and fractional order-models. 
Table 5 shows the settling time and the maximum peak values of the experimental results achieved by these regulators, whose responses were drawn in Figures 12 and 13. From these data, it can be seen that the PI controller designed considering the fractional order model of the system has the best and fastest response in each situation.

Table 5. Parameters of the experimental time response of the PI regulators to a unity step command.

\begin{tabular}{ccc}
\hline Case & Settling Time (s) & Peak Value (mm) \\
\hline Equation (17). Nominal operation point & 8.19 & 1.11 \\
Equation (18). Nominal operation point & 5.02 & 1.097 \\
Equation (17). 10 mm gate opening & 14.4 & 1.30 \\
Equation (18). 10 mm gate opening & 6.3 & 1.25 \\
Equation (17). 30 mm gate opening & 8.8 & 1.02 \\
Equation (18). 30 mm gate opening & 5.9 & 1.03 \\
\hline
\end{tabular}

In order to illustrate the impact of the design of the PI controller in the behavior of the downstream water level, the frequency responses of Equation (12) using Equations (17) and (18) are shown in Figure 14 for comparison purposes. These simulations show that the PI controller designed by considering a fractional-order model of the canal provides a wider bandwidth and, thus, a faster response to step commands, than the PI designed from the integer-order model. This faster response is also illustrated by means of simulation in Figure 15, where it is depicted the evolution of the downstream water level $\Delta Y_{d w e}$ when a unity step signal is applied to the gate opening $\Delta U_{2}$ in the cases of the two controllers.

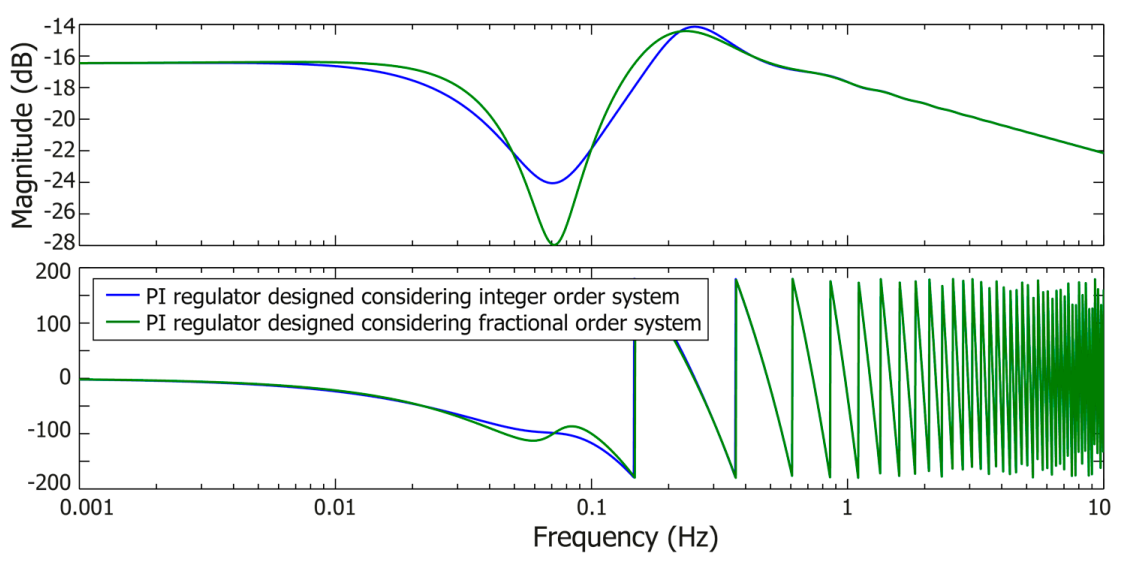

Figure 14. Frequency response of Equation (12) using Equations (17) and (18).

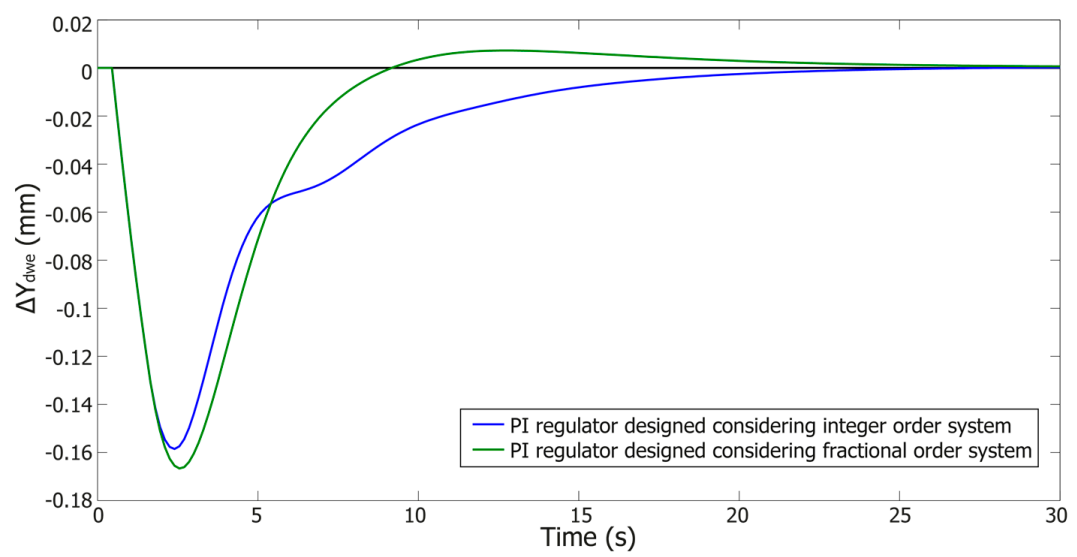

Figure 15. Step response of Equation (12) using Equations (17) and (18). 


\section{Conclusions}

This article has explored the dynamic modelling and control of a laboratory prototype of a hydraulic canal. Its starting point has been two multivariable models of this canal that were experimentally obtained in [43]. The first one was an integer-order model and the second one a fractional-order model.

Based on these models, this article studied the dynamics of this canal assuming that a system to control the water level of the first pool had been implemented. This control system is necessary in order to attain a behavior of the first pool similar to the one of a real canal pool. However, closing this loop yielded, in some cases, complex time responses of the second pool that could not be accurately explained neither by standard first order plus time delay models nor more advanced fractional-order plus time delay models. This article has shown that these complex responses can be accurately described by a TITO fractional-order plus time delay model combined with the mentioned control loop of the water level of the first pool. However, the standard TITO first-order plus time delay model combined with such a control system cannot describe such behavior.

Moreover, the fractional-order model of the first pool reported in [43] has been used to design a new water level control system of this pool that outperforms the previously existing one. It has also been shown that the same controller design procedure applied to the integer-order model of this plant also given in [43] yields a controller with a clearly inferior performance.

The above two studies that have been carried out in this paper demonstrate that incorporating information about the fractional order dynamics of canals in their mathematical models helps to understand the complex dynamics that they sometimes exhibit (at least in the case of our laboratory prototype of a hydraulic canal). Additionally, it allows the improvement in the performance of the control systems whose designs are based on these hydraulic models. It also illustrates that including information about the mathematical model of the canal dramatically improved the performance of any control scheme that could be implemented by using the experience of the operator of the system with no further information.

Our future work includes designing a control loop for the downstream water level of the second loop. The results of this article will have a double impact in the expected performance: (1) because the fractional-order model that mostly defines these dynamics, which is $G_{22}(s)$, also describes more accurately these dynamics than the integer-order model; and (2) because of the impact of the controller of the first pool that has been designed in this work, which yields faster responses than the controllers designed from integer-order models, which allows the assumption that the water level of the first pool remains approximately constant in spite of the disturbance caused by the water discharge on the second pool.

Thus, the results presented in this paper allow us to utilize the laboratory canals currently distributed commercially by different companies to reproduce, at a laboratory-scale, the real-world canals and their dynamics with better accuracy, therefore allowing better training of the operators of these canals, as well as the design of better automatic control systems for these processes.

Acknowledgments: The present work has been supported by the Consejería de Educacion, Cultura y Deportes de la Junta de Comunidades de Castilla-La Mancha and by the European Social Fund with the project POII-2014-014-P.

Author Contributions: All the authors contributed to the development of the experiments, in the data analysis, in obtaining the results, and in the writing and review of the paper. Specifically, Andres San-Millan was in charge of the simulations and the controller design, Daniel Feliu-Talegón of the experiments, Vicente Feliu-Batlle of the mathematical developments, Raul Rivas-Perez of preparing the state of the art, and Vicente Feliu-Batlle and Raul Rivas-Perez of the overall ideas of the exposed research and the general conception of the paper. All the authors have read and approved the final manuscript.

Conflicts of Interest: The authors declare no conflict of interests. 


\section{References}

1. Litrico, X.; Fromion, V. Modeling and Control of Hydrosystems; Springer: London, UK, 2009.

2. The Future of Food and Agriculture: Trends and Challenges. Available online: http://www.fao.org/3/ai6583e.pdf (accessed on 2 August 2017).

3. World Agriculture towards 2030/2050: The 2012 Revision. Available online: http:/ /www.fao.org/docrep/ 016/ap106e/ap106e.pdf (accessed on 2 August 2017).

4. Chaudhry, M. Open-Channel Flow; Springer: London, UK, 2008.

5. Chen, Y.C.; Kuo, J.J.; Yu, S.R.; Liao, Y.J.; Yang, H.C. Discharge estimation in a lined canal using information entropy. Entropy 2014, 16, 1728-1742. [CrossRef]

6. Rivas-Perez, R.; Feliu-Batlle, V.; Castillo-Garcia, F.; Linares-Saez, A. Mathematical model for robust control of an irrigation main canal pool. Environ. Model. Softw. 2014, 51, 207-220. [CrossRef]

7. Monje, C.A.; Chen, Y.; Vinagre, B.M.; Xue, D.; Feliu-Batlle, V. Fractional-Order Systems and Controls. Fundamentals and Applications; Springer: London, UK, 2010.

8. Litrico, X.; Fromion, V. Analytical approximation of open-channel flow for controller design. Appl. Math. Model 2004, 28, 677-695. [CrossRef]

9. Modernizing Irrigation Management-The MASSCOTE Approach. Mapping System and Services for Canal Operation Techniques. Available online: ftp:/ /ftp.fao.org/docrep/fao/010/a1114e/a1114e.pdf (accessed on 2 August 2017).

10. Modernization of Irrigation Systems. Canal Operation Techniques. Available online: http://www.fao.org/ 3/a-ap523e.pdf (accessed on 2 August 2017).

11. Marini, G.; de Martino, G.; Fontana, N.; Fiorentino, M.; Singh, V.P. Entropy approach for 2D velocity distribution in open-channel flow. J. Hydraul. Res. 2011, 49, 784-790. [CrossRef]

12. Singh, V.P. Entropy Theory in Hydraulic Engineering: An Introduction; ASCE Press: Reston, VA, USA, 2014.

13. Feliu, V.; Rivas, R.; Castillo, F. Fractional order controller robust to time delay for water distribution in an irrigation main canal pool. Comput. Electron. Agric. 2009, 69, 185-197. [CrossRef]

14. Malaterre, P.O.; Rogers, D.C. Teaching canal hydraulics and control using a computer game or a scale model canal. In Proceedings of the 13th IWRA World Water Congress, Montpellier, France, 1-4 September 2008.

15. Rivas-Perez, R.; Feliu-Batlle, V.; Castillo-Garcia, F.J.; Sanchez-Rodriguez, L.; Linares Saez, A. Robust fractional order controller implemented in the first pool of the Imperial de Aragon main canal. Tecnología y Ciencias del Agua 2014, 5, 23-42.

16. Weyer, E. System identification of an open water channel. Control Eng. Pract. 2001, 9, 1289-1299. [CrossRef]

17. Schuurmans, J.; Clemmens, A.J.; Dijkstra, S.; Hof, A.; Brouwer, R. Modeling of irrigation and drainage canals for controller design. J. Irrig. Drain. Eng. 1999, 125, 338-344. [CrossRef]

18. Ljung, L. System Identification. Theory for the User; Prentice-Hall: Upper Saddle River, NJ, USA, 1999.

19. Malaterre, P.; Baume, J. Modeling and regulation of irrigation canal: existing applications and on-going researches. In Proceedings of the IEEE International Conference on Systems, Man, and Cybernetics, San Diego, CA, USA, 11-14 October 1998; pp. 3850-3855.

20. Montazar, A.; van Overloop, P.; Brouwer, R. Centralized controller for the Narmada main canal. J. Irrig. Drain. Eng. 2005, 54, 79-89. [CrossRef]

21. Dulhoste, J.; Georges, D.; Besanon, G. Nonlinear control of open channel water flow based on collocation control model. J. Hydraul. Eng. 2004, 130, 254-266. [CrossRef]

22. Rivas-Perez, R.; Feliu-Batlle, V.; Castillo-Garcia, F.J.; Sanchez-Rodriguez, L.; Linares-Saez, A. Control oriented model of a complex irrigation main canal pool. IFAC Proc. Vol. 2011, 44, 2919-2924. [CrossRef]

23. Rivas-Perez, R.; Feliu-Batlle, V.; Castillo-Garcia, F.; Linarez-Saez, A. System identification for control of a main irrigation canal pool. IFAC Proc. Vol. 2008, 41, 9649-9654. [CrossRef]

24. Rivas-Perez, R.; Feliu-Batlle, V.; Sanchez Rodriguez, L.; Pedregal Tercero, D.J.; Linares Saez, A.; Aguilar Mariñosa, J.V.; Langarita Garcia, P. Identification of the first pool of the Imperial de Aragon main irrigation canal. Ing. Hidraul. Mex. 2008, 23, 71-87.

25. Castillo-Garcia, F.J.; Feliu-Batlle, V.; Rivas-Perez, R. Time domain tuning of fractional order controllers combined with a Smith predictor for automation of water distribution in irrigation main channel pools. Asian J. Control 2013, 15, 819-833. [CrossRef] 
26. Caponetto, R.; Sapuppo, F.; Tomasello, V.; Maione, G.; Lino, P. Fractional-order identification and control of heating processes with non-continuous materials. Entropy 2016, 18, 398. [CrossRef]

27. Tian, X.; Fei, S. Robust control of a class of uncertain fractional-order chaotic systems with input nonlinearity via an adaptive sliding mode technique. Entropy 2014, 16, 729-746. [CrossRef]

28. Li, L.; Sun, Y. Adaptive fuzzy control for nonlinear fractional-order uncertain systems with unknown uncertainties and external disturbance. Entropy 2015, 17, 5580-5592. [CrossRef]

29. Rivas-Perez, R.; Castillo-Garcia, F.J.; Sotomayor-Moriano, J.; Feliu-Batlle, V. Robust fractional order control of steam pressure in steam drum of bagasse boiler. Revista Iberoamericana de Automática e Informática Industrial 2014, 11, 20-31. [CrossRef]

30. Zhou, S.; Chen, Y.Q. Genetic Algorithm-based identification of fractional-order systems. Entropy 2013, 15, 1624-1642. [CrossRef]

31. Liu, H.; Yang, J. Sliding-mode synchronization control for uncertain fractional-order chaotic systems with time delay. Entropy 2015, 17, 4202-4214. [CrossRef]

32. Castillo-Garcia, F.J.; Feliu-Batlle, V.; Rivas-Perez, R. Frequency specification regions of fractional order PI controller for first order plus time delay processes. J. Process Control 2013, 23, 598-612. [CrossRef]

33. Barbosa, R.S.; Tenreiro-Machado, J.A.; Ferreira, I.M. PID controller tuning using fractional calculus concepts. Fract. Calc. Appl. Anal. 2004, 7, 119-134.

34. Castillo-Garcia, F.J.; Feliu-Batlle, V.; Rivas-Perez, R.; Sanchez, L. Time domain tuning of a fractional order PI $\alpha$ controller combined with a Smith predictor for automation of water distribution in irrigation main channel pools. IFAC Proc. Vol. 2011, 44, 15049-15054. [CrossRef]

35. Feliu, V.; Feliu, S. A method of obtaining the time domain response of an equivalent circuit model. J. Electroanal. Chem. 1997, 435, 1-10. [CrossRef]

36. Feliu, V.; González, J.A.; Feliu, S. Algorithm for extracting corrosion parameters from the response of the steel-concrete system to a current pulse. J. Electrochem. Soc. 2004, 151, 134-140. [CrossRef]

37. Jesus, I.; Tenreiro-Machado, J.A. Fractional control with a Smith predictor. J. Comput. Nonlinear Dyn. 2011, 6, 031014. [CrossRef]

38. Sierociuk, D.; Dzieliski, A.; Sarwas, G.; Petras, I.; Podlubny, I.; Skovranek, T. Modelling heat transfer in heterogeneous media using fractional calculus. Philos. Trans. R. Soc. A 2013, 371, 20120146. [CrossRef] [PubMed]

39. An LPV Fractional Model for Canal Control. Available online: https://www.hindawi.com/journals/mpe/ 2009/471540/ (accessed on 2 August 2017).

40. Calderon-Valdez, S.; Feliu-Batlle, V.; Rivas-Perez, R. Fractional order mathematical model of an irrigation main canal pool. Span. J. Agric. Res. 2015, 13, e0212. [CrossRef]

41. Garnier, H.; Young, P. Time-domain approaches to continuous time model identification of dynamical systems from sampled data. In Proceedings of the American Control Conference, Boston, MA, USA, 30 June-2 July 2004.

42. Garnier, H.; Mensler, M. The CONTSID toolbox: A matlab toolbox for CONtinuous-Time System IDentification. IFAC Proc. Vol. 2000, 33, 851-856. [CrossRef]

43. Feliu-Batlle, V.; San-Millan, A.; Feliu-Talegón, D.; Rivas-Perez, R. Multivariable fractional-order model of a laboratory hydraulic canal with two pools. In Proceedings of the IEEE 4th International Conference on Control, Decision and Information Technologies, Barcelona, Spain, 5-7 April 2017.

44. Feliu-Batlle, V.; Feliu-Talegón, D.; San-Millan, A.; Rivas-Perez, R. Wiener-Hopf optimal control of a hydraulic canal prototype with fractional order dynamics. ISA Trans. In press. [CrossRef] [PubMed]

45. Litrico, X.; Fromion, V.; Baume, J.P. Tuning of robust distant downstream PI controllers for an irrigation canal pool. II: Implementation issues. J. Irrig. Drain. Eng. 2006, 132, 369-379.

(C) 2017 by the authors. Licensee MDPI, Basel, Switzerland. This article is an open access article distributed under the terms and conditions of the Creative Commons Attribution (CC BY) license (http://creativecommons.org/licenses/by/4.0/). 